\title{
The Complexities of the Automotive Industry: Positive AND Negative Feedbacks in Production Systems ${ }^{1}$
}

\author{
DALE SPEnCER \\ NiKi CARLAN
}

\begin{abstract}
This paper utilizes complexity theory to analyze the implications of systemic changes that have occurred over the last 30 years in the automotive industry. We argue by dint of complexity analysis that the networked automotive production system characterized by just-in-time and lean production creates states far from equilibrium in individual parts manufacturers and assembly plants. Positive feedback creates system disturbances and adverse health and safety issues in the local plant environments. In addition, we examine four mechanisms that serve as negative feedback loops to absorb stresses in local plant environments and rectify health and safety related issues. This paper draws on thirty interviews with health and safety representatives at automotive manufacturing and assembly plants.
\end{abstract}

Résumé. Ce papier utilise la théorie de complexité pour analyser les implications de changements systémiques qui se sont produits pendant les trente dernières années dans l'industrie automotrice. Nous soutenons, au moyen de l'analyse de complexité, que le système de production automoteur en réseau, caractérisé par la production juste à temps et mince, crée des états loin de l'équilibre dans les fabricants de parties individuels et les usines d'assembleur. Les rétroactions positives créent des dérangements dans le système qui causent des conditions défavorables de santé et sécurité dans les environs locaux de l'usine. En plus, nous examinons quatre mécanismes qui servent comme boucles de rétroactions négatives pour absorber ces tensions environnementales, et résoudre les problèmes de santé et sécurité. Ce papier est comprit de trente entretiens avec des représentants de santé et sécurité venant des usines fabricants et d'assemblage automotrices.

1. The authors thank Neil Gerlach, Kevin Haggerty, Jo-Ann Hannah, Kevin Walby, and the two anonymous reviewers for their insightful comments on earlier drafts of this paper. In addition, the authors are indebted to Alan Hall for allowing us to use the data collected on the Health and Safety in the Automotive Sector project funded by Auto 21. Correspondence to: dspence2@ connect.carleton.ca. 


\section{INTRODUCTION}

( ver the last 30 years, the global automotive industry has gone through massive restructuring, with the conversion from a hierarchically oriented, vertically integrated bureaucracy to a horizontal network consisting of lead firms (in the North American context, Ford, Daimler-Chrysler and General Motors and Japanese transplants) and various levels of part suppliers. Concomitant with this shift is the global emergence of just-in-time and lean production and the diminution of mass production. While this new network arrangement promises greater organizational flexibility and these production programs offer efficiency over their predecessors, the combination brings greater levels of complexity. This paper follows the complexity turn in sociology (see Urry 2003; 2005a) and utilizes complexity theory to analyze the impact of these changes on the automotive industry. Complexity theory examines the physics of populations and their emergent and self-organizing systemic properties (Law and Urry 2004; Cilliers 1998). Using the tools developed in nascent theorizations of complexity, we analyze the emergence of the networked automotive production system and the nonlinear effects of this system on local plant environments and the workers who inhabit them. We argue, using complexity analysis, that the networked automotive production system of just-in-time and lean production creates states far from equilibrium in individual parts manufacturers and assembly plants. Lastly, we consider negative feedback mechanisms that attempt to stabilize the system.

Positive feedback, in the form of deficient preventative maintenance and housekeeping, produces health and safety issues in the local plant environments. Joint health and safety committees, collective bargaining agreements, the governmental system, and the International Organization for Standardization (ISO) TS16949 and 14000 standards serve as negative feedback mechanisms to absorb stresses to local plant environments and rectify health and safety related issues.

Our complexity analysis of the North American automotive industry, compared to typical Weberian and Marxist approaches to organizations, offers a theoretically nuanced conceptualization of the impact of internal disturbances on organizations and the effect of those internal disturbances on other organizations within a network. This analysis contributes to the current literature on complexity theory which has not been empirically grounded in the lived experiences of people affected by complex systems.

This paper is structured in six main sections. In the first section, we offer an overview of the contours of complexity theory and situate the 
complexity paradigm within past theoretical, epistemological, and ontological positions. In the following section, the metaphors and tools of complexity are defined. In the third section, we consider complex organizations as spaces of chaos and order and the shift from the vertically integrated bureaucracy to a networked morphology of organizations. This is succeeded by the methods of this study. In the fifth section, based on the data gathered from the health and safety representatives, we present and analyze the networked automotive production system consisting of just-in-time and lean production. In the final section, we examine the impact of positive and negative feedback in automotive production plants.

\section{Contours of CompleXity Theory}

According to Urry (2005a), a complexity turn in the physical "hard" sciences has made its way into the social sciences (see also, Urry 2003; Byrne 2005). This is based on the emergence of a more general "complex structure of feeling" that confronts some quotidian notions of social order (Maasen and Weingart 2000; Thrift 1999). Derived from chaos and systems theory, complexity theory is concerned with changes that do not fit into a simple linear law of distinct cause and corresponding effect (Byrne 1998). Unabashedly systems oriented, complexity theory stresses that there are various networked time-space paths, often immense disproportions between causes and effects, and volatile yet irrevocable patterns that seem to typify all social and physical systems (Urry 2003:7).

Complexity is a theoretical framework and ontology, insofar as it is grounded in the ontological claim that the contemporary, globalized world is complex. Systems in complexity theory occupy the space between order and chaos, that is, they are in balance (Cilliers 1998; Urry 2003,2005 b). ${ }^{2}$ System components are never fully stabilized nor do they dissolve into anarchy. As Urry (2003:22) states, "there is a kind of "orderly disorder' present within all such dynamic systems." Complexity theory is different from chaos theory which deals with simple, deterministic, nonlinear, dynamic closed systems that are sensitive to initial conditions. Complexity theory focuses on nonlinear open systems that

2. Within the complexity literature, there is a debate regarding the nature of complex systems. On one side, Byrne (1998) contends that complex systems operate at "the edge of chaos." Following Cilliers (1998), the position that we hold is that complex systems operate between order and chaos. The main point of contention, as far as we are concerned, is that a system that only behaved chaotically, or at the edge of chaos, would be useless and cease to produce anything. On the other hand, a system characterized by order would have very little capacity for adaptation and result in death of the system. 
interact with their environments (Gatrell 2004). Open systems interact with other systems and their environments producing various nonlinear effects.

In contradistinction to positivistic linear accounts, and crucial to complexity theory, is the position that knowledge is inherently local and contextual rather than universal (Byrne 2005; Cilliers 1998). Challenging the nomothetic project of positivism, complexity theory is dynamic, primarily concerned with description and explication of patterns of change in a given system and its particular local effects (Byrne 2005). Complexity theory also differs from the systems-based theories of Parsons and Luhmann. While systems theory focuses on problem solving, prediction, and control, complexity analysts undertake exploratory research focusing on explanation and understanding. In addition, while relations and networks figure in the work of systems and complexity theory, complexity places central importance on emergence and hybrids that result from systems (Gatrell 2004).

\section{Tools and Metaphors of Complexity Theory}

This recent complexity turn has been labeled (Urry 2004) the "new social physics." Metaphors and concepts are often drawn from quantum physics and its emphasis on nonlinear systems. Complexity theory places systems at the centre of analysis, examining how systems adapt and evolve as they self-organize through time (see Mitleton-Kelly 2003). A system in complexity theory comprises various components and subsystems embedded within systems that have their own respective components. An example of a system in social science (Gatrell 2004:2662) is a transport network that transfers people and materials from one place to another. Systems, then, include hybrids of social and material components, or in Lash and Urry's (1994) conceptualization, they are "material worlds." In a global sense, the world comprises various systems, functioning at manifold levels and scales, each comprising the environment for each other (Urry 2003; 2005b). A system is characterized as complex only when it consists of such intricate sets of nonlinear relationships and feedback loops that it cannot be analyzed as a whole (Cilliers 1998:3). ${ }^{3}$

3. With respect to the difference between complicated and complex systems, Cilliers (1998) is particularly instructive. A system is complicated when it has a large number of components and performs sophisticated tasks, but in a way that can be analyzed or modeled fairly accurately. A complex system can be differentiated from a complicated system insofar as it is made up of extremely intricate sets of nonlinear relationships and feedback loops; only 
Focus is also on the effects of relations and connections between different elements.

A central tenet of complexity theory is that all living and social systems involve a process of self-making and self-organizing or autopoiesis. Autopoietic systems involve a network of production processes in which the role of each component is to participate in the production or transformation of other components in the network. In this sense, the network continually makes itself (Byrne 1998; Capra 1997; Prigogine 1997; Cilliers 1998; Gatrell 2004). A prime example of an autopoietic system is the Internet (Urry 2005b:246-7). Users across the globe, not business or state bureaucracies, are the key producers of the technology. "[The Internet] possesses an elegant, non-hierarchical rhizomatic global structure and is based upon lateral, horizontal hypertext links that render the boundaries between objects within the archive endlessly fluid" (Urry 2005b:247). From autopoietic systems, new structures and behaviours emerge vis-à-vis the continual interaction of system components (Holland 1998; Cilliers 1998).

Autopoietic systems characterized by emergence and hybridity are also far from balanced. Systems in complexity theory are nonlinear insofar as there is no consistent relationship between a specific cause and corresponding effect. Rather, the same cause, in specific circumstances, can produce drastically different kinds of effect (Cilliers 1998; Byrne 1998; Urry 2003; 2005b). Emergence signifies what happens when there is movement from one aggregation level to another. Organizing and organization, then, are names often ascribed to movement between aggregation levels (Letiche and Boje 2001). Emergence can be political engagement within a given system, sometimes resulting in systemic patterning.

With the emergence of patterns within networks, attractors are established. An attractor is a control mechanism in a dynamic system which does not move through all possible parts of a phase space but instead occupies a restricted part of it. However, when a specific attractor or key control parameter in a system changes its value by an amount three times greater than the value in the previous cycle, it becomes a Lorenz or strange attractor. In a dynamic system, strange attractors produce massive effects in all the other components in the system; small causes can have massive (nonlinear) system-wide effects. Through path dependence, these effects can create changes to the entire system; irreversible contingent events set in motion institutional patterns with long-term deterministic properties. An example of path-dependence is the introduction of the fax machine in the office, creating a tipping point in the international communicative

certain aspects of these systems can be analyzed at any one time. Attempts to predict behaviour of complex systems results in distortions. 
system and making fax machines a necessity in all Western offices (see Gladwell 2000).

Based on the nonlinearity of causes and effects in systems, complexity theory stresses positive feedback loops rather than negative feedback loops. Positive feedback loops can exacerbate initial stresses in the system, preventing it from restoring equilibrium by absorbing shocks (Urry 2003:13; see also, Hayles 1991; 1999). Positive feedback happens when a change tendency is dramatically reinforced rather than dampened down; network composition removes the central hierarchical governing structure which could reduce the continual stresses to the system caused by positive feedback (Urry 2003). Positive feedback loops set events in motion that can produce irreversible and uncertain outcomes, creating system failure and breakdown. It is only through negative feedback loops acting as control mechanisms that these system effects are dampened down.

\section{The Complexity of Organizations}

Perrow (1984) in his now classic work, Normal Accidents, employs the language of complexity to explain accidents in organizations. He shows that in tightly coupled systems of production, recovery even from minor initial disturbances is impossible. The consequences spread rapidly, chaotically, and irreversibly through the system, producing system accidents rather than accidents caused by individual error (Perrow 1984:11). In this same vein, Serres (1982:127) states that organizations inhabit the space between "order and noise, between disorder and perfect harmony." Law (1994:132) argues that organizations are based on ordering and "ignoring; simplifying; fixing; what is complex for a moment in a stable form." More recently, Clegg, Kornberger, and Rhodes (2005) in their analysis of the "learning" organization, posit that organizations endemically occupy the space between order and chaos. They assert that the ontology of organizations is one of increasing complexity and reducing it, ordering and disordering, and these characteristics are interdependent, supplementary, and parasitic (Clegg, Kornberger, and Rhodes 2005:153). Out of this imbroglio of chaos and order, organizations are continually becoming, or in complexity terms, new organizational forms emerge.

Along with the recognition that organizations are at the intersection of chaos and order, there has been recognition that organizations have entered into a network paradigm (Borgatti and Foster 2003; see Beck 2000) or, as Castells (1996; 2000) puts it, the "network enterprise." With the shift from Fordist production systems to post-Fordist produc- 
tion systems, there was a concomitant shift from mass standardization to flexible customization at the core value of production, distribution, and consumption (Barney 2004). Spreading across and restructuring organizations, adding to the complexity of organizational life, this shift engendered the model of the network: a web of interconnected firms or nodes organized within specific systems of production. The nodes are interconnected by multiple, easily reconfigured ties through which a variety of flows can pass; the interconnection of computers emerges as particularly apt for achieving flexibility in economic systems. This new network configuration is marked by the agility and flexibility necessary to react to continually changing demand cycles, markets, and technological innovations (see Castells 1996; 2000; 2001; Barney 2004). This network morphology has virtually wiped out the insulated and intrinsically rigid, vertically integrated bureaucracy with its slow-moving formal processes and layers of middle management. Apologists for bureaucracy like Du Gay (1994; 2000) and Kallinikos (2004) defend an organizational form that has not existed for some time.

However, this new, networked organization is not without its problems. The path dependence of the network organization form brought with it disequilibrium unseen in the vertically integrated bureaucracy. Networks are autopoietic, insofar as nodes come together for specific projects. These formations rely on all other nodes in the network and in order to function, the production systems of all of the nodes must run smoothly. Since speed and flexibility are necessities, small problems in one node's production system can have massive effects on the rest of the nodes within the network. Positive feedback can send the network into a state of extreme disequilibrium (Urry 2003). Consequently, and not unrelated, system dysfunction can detrimentally affect the subsystem phase spaces of individual nodes.

The following offers a complexity theory account of the networked automotive production system and looks at how disturbances in one production system can create disequilibriums within their own plants or phase spaces and in other firms' or nodes' phase spaces in the network. Through a complexity analytic, the remainder of this paper examines the role of just-in-time and lean production in creating specific disequillibriums within different leveled production plants or phase spaces of the networked automotive production system. We argue that positive feedback engendered by these systems cause health and safety problems, most acutely in the area of preventative maintenance and housekeeping, sometimes resulting in repetitive strain injuries. Lastly, we examine several components of automotive manufacturing environments that act as negative feedback mechanisms. 


\section{Methods}

This research was conducted in southern Ontario, a hub of automotive manufacturing in Canada, between 2001 and 2004. During that period, the automotive sector was relatively stable. The research was conducted prior to a period of major restructuring, plant closures, and significant layoffs in late 2005 and 2006. Our cohort consisted of union health and safety representatives from Canadian Auto Workers local unions. These representatives regularly participate in joint health and safety committees. They were either elected in local union elections or appointed by the union leadership. Most of the representatives had more than 5 years' experience in health and safety; some had more than 20 years of experience. The majority of the subject companies had been in business for about 30 years; one of the newer firms was established in the late 1990s. Health and safety representatives were drawn from Original Equipment Manufacturer (OEM) vehicle assembly plants, Tier 1 and Tier 2 part supplier plants. The firms were engaged in all aspects of automotive manufacturing including tool and die operations, metal stamping, foam injection, cleaning, and assembly.

The process of lean production was selectively phased into the automotive manufacturing sector over a period of 20 years beginning sometime in the late 1970s (Landsbergis, Cahill, and Schnall 1999; Lewchuck and Robertson 1996). As Lewchuck and Robertson (1996) identified in the Ontario jurisdiction and other authors (Young 1992; Clement and Myles 1994; Kochan and Lansbury 1997; Rinehart, Huxley, and Robertson 1997) have noted in multiple jurisdictions, the cultural, political, and economic climates all influenced the extent to which lean production was introduced and accepted by different work places. The fluid introduction of lean production made it amenable to our qualitative methods. Following their systematic review of the health and safety literature, MacEachen et al. (2006) argue that a qualitative approach adds an important dimension to health and safety research and is gaining general acceptance in the field of health research. This includes the opportunity to discover the workers' indigenous knowledge of their environment. Kramer and Wells (2005) describe this kind of knowledge as both political and instrumental, aimed at implementing a joint goal: modifying work processes and improving the health of workers.

Health and safety representatives and local union presidents were asked to complete questionnaires. We made phone calls to encourage responses and finally received responses from more than 50 percent of potential union locals. Respondents were asked to participate in an interview and thirty agreed. Semi-structured interviews, lasting about one 
hour in length, were conducted in the union office, respondent's homes, and at the workplace, where workers had access to private offices. The interviews were focused on general details about their respective plants and health and safety related issues. Data from the interviews were analyzed and the themes were compared with the questionnaire responses. Worker representatives' responses indicated that housekeeping and preventative maintenance were critical factors in maintaining a safe workplace on the one hand and a source of many of the accidents their colleagues suffered in the workplace. Supplementary structured interviews were conducted with many of the worker representatives to clarify their understanding of housekeeping and preventative maintenance, further confirming their views on the role of housekeeping and preventative maintenance.

\section{Lean Production and Just-in-Time}

Beginning in the 1980s, the vertically integrated Fordist production model was criticized for its rigidity and lack of flexibility in continually changing and diverse global markets (see Piore and Sabel 1984; Deyo 1996:2; Beck 2000:77). Lead firms began to contract out as a method of reducing costs, improving asset efficiency, and increasing profits in the global competitive markets (Clott 2004; Zullo 2004). The resultant production system, displacing the older vertically integrated bureaucracy, was a horizontal network comprising lead firms (in the North American context, Ford, Daimler-Chrysler and General Motors, and Japanese transplants) ${ }^{4}$ and different levels of "tiered" part supplier firms (Castells 1996:160, 164; Sabel 1993; Casper and Hancke 1999:964). ${ }^{5}$ As a result of the restructuring of the industry, in an autopoietic fashion, there was the creation of a networked automotive production system, comprising an

4. Since the beginning of the 1980s, Japanese transplants have become more prominent in the North American automotive industry. Rutherford (2000:740), indicates the growing number of Japanese plants in the US and Canada, arguing that in comparison to North American assemblers, Japanese transplants are pursuing supply relations characterized by more information transfer and the development of longer term contracts with their Tier 1 part suppliers.

5. To understand the tiering system, according to global value chain analysts (Gereffi 1994:97; Humphrey 2003:122), products have to go through a succession of activities in the passage from raw materials to the market. Likewise, products go through a range of stages within the production chain to add more "value" to the part as it makes its way to the customer. Consequently, tiers denote the level to which value is added to a part destined for a car. For example, Tier $2 \mathrm{~s}$ and $3 \mathrm{~s}$ are usually involved with the manufacturing of raw materials that are sent on to the Tier 1 suppliers for assembly. 
elaborate supply chain network, in which nodes coalesce around specific projects (Castells 1996; 2000).

Along with the shift to a networked automotive production system, two main production programs have emerged, characterizing this new system: lean production and just-in-time. Facing near economic bankruptcy after WWII and plagued by poor production rates, Japanese carmaker, Toyota, developed these production programs. In a path dependent fashion, by the mid-1980s, they had spread across the world (Womack, Roos, and Jones, 1990). All automotive plants in this study operate under just-in-time and all have characteristics of lean production.

Lean production, compared to mass production, relies on half the human effort in the factory, half the manufacturing space, half the investment tools, half the engineering hours, and half the time to develop new products. Accordingly, leading proponents of lean production posit several principles, which include teamwork, communication, efficient use of resources, the elimination of wastes, and continuous improvement (Womack, Jones, and Roos 1990), resulting in more value for the customer. With the diffusion of lean production into North American and European automotive firms in the 1980s, many analysts suggest that these principles are not completely taken up in plants; rather firms adopt certain aspects that are perceived to be beneficial, while operating traditionally in other areas (Seppala and Klemola 2004).

Certain elements of lean production, especially standardization and work intensification, were derived from principles of scientific management promoted by F.W. Taylor (see Braverman 1974). This has led some to argue that lean production is a myth, or rather, that lean production is no more than hyper-Taylorism (see Linge 1991). While lean production places emphasis on reducing labour cost by increasing the pace of work, it also attempts to integrate workers' input into the organization of work and work processes. There is a resulting shift in responsibility onto workers to enforce quality control standards and a high degree of integration of conceptual activity and the execution of production tasks (Kochan and Lansbury 1997). Due to lean production's emphasis on physical strength and mental skills, it should be viewed as distinctly different, and significantly contrary to Taylorism.

The most salient feature of lean production is the efficient use of resources. This is achieved by adjusting human resources, removing restrictive rules on work assignments (job classifications), developing multifunctional workers, job rotation, and widening or narrowing the range of jobs done by each worker (Rinehart, Huxley, and Robertson 1997:27). Accordingly, a key organizational element of a truly lean pro- 
duction plant is that the utmost number of tasks and responsibilities are transferred to those workers actually adding value to the car on the line.

Eradication of waste in the production system means continually removing actions that are not required in product production and consequently, do not add value to the customer (Seppala and Klemola 2004). The target is to produce a tighter, more fluid, production system through operations, design, or structural changes to the production process. Lean production systems comprise a tighter coordination of production and the elimination of wasted time and space (Leslie and Butz 1998:360). A worker under lean production is assigned nonproduction responsibilities in addition to normal production requirements, maximizing the number of tasks performed. Increasing the number of tasks, in turn, decreases the rest time between work cycles. A worker in this environment is not allocated slack time; it is required, as Womack, Jones, and Roos (1990:103) mention, that "every worker try very hard."

Coupled with and directly related to the continual emphasis on the eradication of waste is the use of just-in-time delivery (JIT), devoted to the seamless connection between the production system and the customer. Inventories and buffers are reduced; the aim is to minimize the use of buffers and rest time by exposing weaknesses in the production system and addressing them immediately (Fairris and Tohyama 2002). Under JIT, parts are pulled through the production system destined for the customer. The "pull" within JIT then serves as the driver of the production system. The goal is to synchronize timing to meet the customers' needs for parts on an as-needed basis (Womack and Jones 1996).

\section{Positive and Negative Feedback}

\section{Positive Feedback Loops}

Positive feedback occurs when a change tendency is reinforced rather than dampened down. Network composition removes a central governing hierarchical structure which could dampen down the stresses to the system and between systems caused by positive feedback (Urry 2003). Positive feedback can intensify initial stresses in complex systems, leading in some cases to endemic failures (Urry 2003; see Perrow 1984). In this study, it was found that positive feedback has a compounding effect leading to disequilibriums throughout phase spaces in the system. With the continued emphasis on cutting out nonvalue-added labour, firms have cut housekeeping and machine maintenance staff (see, Rinehart, Huxley, and Robertson 1997). Health and safety representatives report that housekeeping and preventative maintenance issues can pose problems 
to the networked automotive production system and create health and safety problems. In the cases where there was a reduction in preventative maintenance staff, health and safety representatives stated that it had a detrimental impact on the production system.

Interviewee \#19: I've heard of it where I am where we affect the customer. So we're the third or second person in the food chain. We'll in fact, the customer, [names company] would be a name that comes to mind, or [names company] who, we will supply [names company] or [names company] subsidiaries that manipulate a part before it goes on. So we've shut them down in the past due to quality or production issues.

Interviewee \#2: When you downsize all your departments, something has to be impacted by that decision. And as a result, some things go unchecked for longer periods of time. If you have the resources in place of course you can have your preventative maintenance program a hundred percent and another area a hundred percent. But when you cut back, it tends to affect that area. So you kind of, you can, so you find yourself in a situation where you're repairing things as they break down or as needed. You're not looking for problems at that point.

Interviewee \#26: So the problem is with the just-in-time and a lack of maintenance is when the line has been down for four hours, now instead of making four hundred parts they'd really like to make five hundred parts an hour. And some people will try ... some people will hurt themselves trying.

Interviewee \#17: Well yes, in some cases they don't have the manpower or the maintenance men [sic] or the tool makers to do preventative maintenance. They just do maintenance just to keep it going, you know. So, and at times, you'll have like an engineer or something like that, he works steady days. Well the other night, he worked until ten o'clock at night, you know because something would break down. New technologies. Big thing in the industry now. There's all different kinds of new safety devices, protective tooling that is implemented. I might be getting a little bit off topic here, but they just put out one fire and another one is burning them right in the butt right away.

These responses show that under lean production, where there is an insufficient preventative maintenance staff, internal disequilibriums are created in the production system. Where on-time delivery to other nodes in the network is crucial, disturbances to the system reveal the fragility of lean production and just-in-time (see Womack, Jones, and Roos 1990:103). Specifically, in mass production systems, parts were stockpiled "just in case," but with limited stockpiling in just-in-time, the networked automotive production system can be shut down when firms 
in the network have machine breakdowns. When not addressed, machine breakdown can momentarily slow the production system and, as shown in the first two responses, create a debilitating effect to the system. The third respondent revealed that the combination of reduced staff and the intensification of the production system associated with just-in-time creates situations where machine breakdowns can have an adverse affect on the efficiency of the production system and affect delivery quotas as well as the bodies of workers. In the fourth response, stresses to the networked automotive production system, in the form of machine breakdown, becomes positive feedback where the system is continually faltering.

The literature on just-in-time and lean production has generally shown that the combination intensifies the work process (see, for example, Leslie and Butz 1998; Yates, Lewchuck, and Stewart 2001; Fairris and Tohyama 2002). Part of lean production is transferring the utmost of tasks to on-the-line production workers. In some cases, workers have the added responsibility of housekeeping and preventative maintenance duties (Graham 1995). The following response reflects the work intensification that results from just-in-time and lean production with the added responsibility of housekeeping duties.

I: Why would they want you to have smaller quantities more often?

Interviewee 26: Inventory turnover. What we were talking about earlier, leaner production, just-in-time. It's kind of, instead of having a six months supply of parts on hand, we're down to about four weeks supply of parts. Order less quantities, less inventory to hold, more repetitive movement on the parts.... The most common problem for us is repetitive strain, back injuries ... you're doing the same part over and over and over within a cycled time, maybe once a minute or once every forty-seven seconds....

Interviewee 5: In terms of housekeeping, which is sort of a requirement for everybody and their individual workstations, there is a lot of pressure to produce more. And because there's pressure to produce as much as possible, you'd be less inclined to keep your area in good order because, because you're, you're spending all your energies towards maintaining an expected production standard. So therefore, something usually suffers.

The first case shows how the intensification of the work process associated with just-in-time and lean production results in repetitive strain injuries. With production constantly paramount over housekeeping, the second representative reveals the endemic nature of housekeeping problems. In this case, the intensification of the work process left little time for housekeeping tasks, which inevitably suffered. The necessary task of maintaining order is not addressed, creating a chaotic production environment filled with clutter. 
Nichols' (1997) examination of industrial injuries in Britain found that most serious injuries resulted from slips, trips, and falls in the workplace. Representatives in this study indicated that housekeeping and preventative maintenance-related hazards were, in some cases, the foremost health and safety problem in their respective plants. The following responses reflect the impact of reduced preventative maintenance and janitorial staff on health and safety.

I: In terms of your plant, what's the biggest health and safety issue?

Interviewee 11: At the health and safety meeting, that I'm trying to think of an umbrella, sort of, 'cause we've got so many small ones, so many small issues we're continually chasing. I guess I would have to say preventative maintenance. That's where everything seems to sort of fall apart, that doesn't get done, the preventative maintenance doesn't get done, so then you are running into hazards and then accidents, and then it just grows from there because they don't have the time or the desire to do the preventative maintenance.

Interviewee 16: In this manufacturing process, a lot of coolants are being used. The coolants, by their nature, leak out from machines. They leak onto the floor. The walking, the working surfaces and it is constant problem with reduced housekeeping, getting the floors clean so you can prevent slips and trips and falls, etcetera. And getting them on time. Slips and trips are one of the largest contributing factors to industrial injury in the facility I represent.

I: Now as you know this is a health and safety survey and the first question I have for you is, what is the most important health and safety issue in your work place?

Interviewee 22: I would say coolant leaks from the machines due to the lack of preventative maintenance. Because we only have one janitor, days and afternoons. We don't have one on midnights and they're rarely being cleaned up, the spills. So they're looking at it as slip and fall accidents.

The first response shows that the reduction in preventative maintenance staff leads to machine break downs, which, in turn, cause hazards and ultimately accidents. In both the second and third responses, the reduction in housekeeping and preventative maintenance staff creates a compound effect where spills occur, but are not cleaned up, ultimately resulting in slip and fall accidents. All open systems interact with their environments and can cause states of disequilibrium, as is evident in this study. The combination of just-in-time and lean production has the effect of intensifying the work process, causing the system to falter in other areas like housekeeping and preventative maintenance. As shown in these responses, positive feedback can have a cumulative effect caus- 
ing further stresses to the system and its environment. The phase space of the production system becomes chaotic, ultimately causing physical harm to the individuals inhabiting the phase space. Only through negative feedback is there restoration of some order.

\section{Negative Feedback Loops}

Negative feedback counteracts positive feedback and acts as a control mechanism to move systems closer to a state of equilibrium. In Parsonian theory, negative feedbacks in organizations are internal control mechanisms which maintain systems in states of equilibrium. Key to this are cybernetic systems that transfer information, of disturbances and other important information, continuously throughout an organization (Parsons 1977). Whether negative feedbacks loops were ever as effective at restoring order as Parsons claims is a debatable point, but the shift to networked forms of organization and the globalization of the automotive industry has significantly reduced the effectiveness of these older control mechanisms within organizations.

While these changes were occurring in the automotive industry, the occupational health and safety environment was undergoing change. In Canada and around the world, governments began to recognize the significance and cost associated with poor health and safety practices. In the late 1970s, the Ontario government introduced an "Internal Responsibility System" to augment services provided by the Ministry of Labour (Lewchuck, Robb, and Walters 1996; O'Grady 2000). The workplace parties were required to work together to promote safe work environments, while regulatory enforcement was left to the government. Since the late 1990s the government's responsibility has been shared by the Workplace Safety Insurance Board (WSIB), which took over primary responsibility for education, research, and prevention, while the Ministry of Labour continues to identify companies that have a record of noncompliance with the Occupational Health and Safety Act (OHSA). The WSIB is a statutory body which provides compensation to most workers in the province from premiums collected from employers.

Participants' responses revealed a complex structure of health and safety responsiveness consisting of four separate negative feedback loops including (1) Joint health and safety committees, (2) collective bargaining agreements, (3) the governmental system, and (4) the ISO TS 16949 and 14000 series standards. In the following analysis, we examine these four negative feedback loops and their impact on housekeeping and preventative maintenance and health and safety more broadly. 
The first and arguably most effective negative feedback mechanism is the joint health and safety committee. In companies with more than 20 employees, these committees are mandated by law. They consist of management and union representatives. These forums provide an opportunity for workplace parties to resolve issues that recur in the work environment and require systemic management attention. ${ }^{6}$ Joint health and safety committees process and act on the information gleaned from the workplace and external knowledge sources (see Hall et al. 2006). A health and safety representative reveals the cybernetic nature of gaining information on health and safety issues:

Interviewee \#4: Well we've got four ways that we get information to our, we have task meetings weekly and then our monthly health and safety meetings. For our weekly task meetings we draw information from accident reports, so an accident has already happened. A hazard or a potential hazard or near miss. Our monthly inspections. And then just workers bringing it to our attention. Or sometimes it's even supervisors because our supervisors get nowhere with our management, so they come to the worker rep and get things addressed that way.

As shown in this response, information flows from the workers to the committee in manifold ways and helps to keep the committee abreast of the issues in the factory environment. Often in a direct, hands-on manner through inspections or through shop floor workers reporting to the representatives, information flows up through the organization so that it can be processed by the members of the committee. On the other hand, health and safety representatives use sources external to their organization to be processed by the joint health and safety committees. This is reflected in the following two responses:

Interviewee \#25: We've got a lot of, like when we have our annual conferences in Port Elgin, we've got a lot of people to draw from. And we have, usually we have an idea sharing seminar where somebodys [sic] worked at Ford, where something happens which [is the] same in all the plants. And then we have smaller plants that don't have the big representation that are invited to these conferences and they can pick up from that as well. And

6. Joint health and safety committees in Ontario began in the 1970s as a consequence of concerns of the United Steelworkers of America (USWA), which represented uranium miners. Through the collective bargaining process, a joint occupational health and safety committee was created at INCO, the county's largest nickel mine. These original joint health and safety committees acted in response to individual workplace issues and what happened in Sudbury did not necessarily influence what was going on in northern Manitoba. Eventually the Ontario government mandated committees for all employers with more than 20 workers (Occupation Disease Panel 1997). 
the networking is fantastic ... I don't see much of a downside in networking because it's a fantastic resource and it's easy.

Interviewee \#27: ... they were complaining of sneezing up black stuff. You got ventilation but it's on the wrong end of the source, it's past the worker and it's totally insufficient. I've shown them on paper where they ...

I: So do you guys draw a diagram and take it to the committee?

Interviewee \#27: No I went on the Internet and got pictures of what I wanted and showed where the problems are, that the ventilation is actually behind you and the smoke's got to go past you to get to the ventilation and it's not working. You got to make some changes. We got it in front of them now it's here.

In the first case, conferences and meetings with other health and safety representatives serve as the basis for information transfer with other representatives situated in other phase spaces in the networked automotive production system. In the latter case, the representative used information acquired through the Internet to convince management of necessary changes to the ventilation. In both cases, information flows into the phase space for the representative to be knowledgeable about, and make changes to, existing health and safety conditions. In this sense, health and safety knowledge transfer coincides with, and is complementary to, the networked nature of this system. Under mass production, health and safety knowledge remained insular to a firm, whereas the networked nature of this system makes it more amenable to knowledge transfer (see Kramer and Wells 2005).

Health and safety representatives noted the power of the committee and the utility of gathering information from the shop floor to rectify health and safety issues (c.f. Weil 1999; Eaton and Nocerino 2000). This is reflected in the following response:

Interviewee \#29: Well, the joint health and safety committee is like a driving force behind it and has a lot of power as far as recommendations and because we're trained in health and safety, we have a little more insight into a lot of things that the engineers may have or the management directors, etcetera.... In my job, I only worry about our joint health and safety committee on the floor. And with the power you have, I've learned is that it's all business. The power as the committee worker rep you have is in your communication to the work force, that's the power that management responds to. Management will respond to something that's blatant, but they overlook a lot of, many, many things because they want, the job won't make them money. 
Information collected through these processes, and the continual communication with the workforce, offers the union representatives on the committees the political authority to lobby for changes to health and safety conditions. This response highlights an element of this negative feedback loop which is its weakness, that is, union representatives are reliant on cooperation from management to make positive changes in health and safety (c.f. Lewchuk, Robb, and Walters 1996). In this response and others in this study, health and safety representatives noted that if health and safety issues did not align with the economic concerns of management they would not be adequately addressed (c.f. Shannon, Robson, and Sale 2001:327). Other respondents noted that because housekeeping and preventative maintenance were ongoing issues, the committee responsiveness was not adequate to quell these day to day problems.

The second negative feedback loop, collective bargaining agreements beyond pay issues, is utilized by health and safety representatives to resolve long-standing health and safety issues. The Canadian Automotive Workers (CAW) Union began to aggressively negotiate health and safety issues in the 1990s following its separation from the UAW (Occupational Disease Panel 1997). Collective bargaining is now used to institute health and safety policies and to make changes that increase the company's responsiveness to health and safety issues (Cutcher-Gershenfeld, Kochan, and Wells 1998; Aidt and Tzannatos 2002). Often health and safety policies emerge from political action in some phase spaces or organizations and pattern across other organizations within the networked automotive production system. This is referred to as pattern bargaining (Carlan et al. 2007). The integration of lean production greatly reduced housekeeping and preventative maintenance staff making it a significant issue in collective bargaining negotiations. This is reflected in the following response:

\section{I: And has the number of janitors changed recently?}

Interviewee \#7: No. We tried to in bargaining, a third one, but they wouldn't go for it. So hoping through health and safety we can push them to hire a third janitor.

I: And when you tried to bargain it, how did you, did you bargain under health and safety? Did you try that way or how did you, what was your push during the bargaining ...?

Interviewee \#7: Yes, absolutely, straight open through plant cleanliness, use of coolant, sanitary washrooms on weekends 'cause we run 24-7 at our place.

While collective bargaining strength lies in its efficacy of instituting health and safety policies, its effectiveness, like joint health and safety 
committees, is contingent on the management and worker relations. Many of the participants in this study revealed that management used "market pressures" and moving facilities to cheaper areas of the globe as a fulcrum to keep health and safety expenses to a minimum.

The third negative feedback, the governmental system, insures companies in the case of workplace injuries and is responsible for accident prevention (Campolieti and Lavis 2000; Bennett 2002). This negative feedback comes from the Ministry of Labour and their inspectorate and the WSIB who work in tandem with the ministry to identify firms with poor health and safety conditions. The WSIB identifies companies that have particularly poor accident records in cost, frequency, and/or severity; the Ministry of Labour identifies companies that have a record of noncompliance with the OHSA. A company identified for a Section $82^{8}$ evaluation by data sets from either the Ministry of Labour and/or the WSIB is subject to a WorkWell audit. ${ }^{9}$ In this case, employers are notified and meet with an evaluator, who examines the occupational health and safety program, observes the employer's workplace practices on site, and interviews workers. If the firm fails a second audit, there is an increase in the firm's base annual premium, depending on the extent and seriousness of the health and safety shortfalls. The impact on a company's insurance of failing or passing a WorkWell audit, highlights its salience. Despite the potential of the WorkWell audit to serve as a battery of control (see Power 1997), assuring compliance of firms to a comprehensive health and safety standard, the areas covered in the audit have notable limitations. For instance, the audit does not make provisions for housekeeping duties and therefore, a plant may be riddled with housekeeping issues and still pass an audit.

The fourth negative feedback loop is the ISO/TS 16949 and ISO 14000 series standards (see Kartha 2004; Harrington 1999). In the North American context, largely due to the restructuring that has occurred, Daimler-Chrysler, Ford, and General Motors have imposed quality and environmental standards upon their suppliers. All part supplier companies in this study were required to be certified in the quality assurance standard, ISO/TS 16949, and the environmental standard, ISO 14000, to

7. In their survey of union and management negotiators across the United States, Cutcher-Gershenfeld, Kochan, and Wells (1998) also found that management threatened to replace workers and close plants in collective bargaining.

8. Section 82 of the occupational health and safety act (OHSA) permits the WSIB to evaluate health and safety conditions in workplaces as factors in estimating the likely accident experience of a given company. Insurance premiums reflect the level of industrial risk of a firm.

9. A WSIB WorkWell audit is a systemic plant-wide evaluation of a given workplace's health and safety conditions. 
supply to Original Equipment Manufacturers. These standards require suppliers to have processes for every work procedure in place, assuring quality and environmental responsiveness, and are audited for compliance. Participants in this study saw these standards as contributing to a greater level of order and to the formulation of processes to react to health and safety concerns, in some cases preventative maintenance and housekeeping issues. Some participants claimed that they noticed no change due to standardization and that management placed emphasis on parts of the standards that are efficacious in increasing productivity (c.f. Bennett 2002; Spencer 2007). In addition, as interviewee 3 explained to us, housekeeping and preventative maintenance issues may have only been attended to the week before the performance of audits.

The criticisms made of the preceding negative feedback mechanisms do not suggest that if one, or any combination of them, were able to rectify any of the noted weaknesses, they would emerge as a veritable deus ex machina, moving plants dramatically closer to equilibrium. Production systems will always operate in disequilibrium and will often have detrimental impacts on their local environments. Negative feedback in systems maintains a level of order and counteracts the impact of system disturbances on phase spaces. In this example, joint health and safety committees, collective bargaining, WSIB, and ISO TS16949 and 14000 standards act as negative feedback mechanisms, lessening the adverse effects on health and safety in local plant environments. In addition, a move towards integrating housekeeping and preventative maintenance more prominently in these negative feedback mechanisms, health and safety agendas could have the effect of counteracting lean production and its reduction in staff. In turn, this may have the effect of reforming the existing production system and repositioning housekeeping and preventative maintenance duties as not ancillary to the system, but rather as essential to its functioning. In line with complex systems, emergent processes, in this case intra- and interorganizational politics, hold the promise of future, innovative negative feedback loops that may be added to or replace the negative feedback considered here.

\section{Conclusion}

In this paper, we argued, using complexity analysis, that the networked automotive production system characterized by just-in-time and lean production produces states of disequilibrium in individual parts manufacturers and assembly plants and, through positive feedback, creates health and safety issues in the local plant environments. In addition, we 
showed that joint health and safety committees, collective bargaining, the governmental system, and ISO TS16949 and 14000 standards serve as negative feedback mechanisms to absorb stresses to local plant environments and work to rectify health and safety related issues. Analyzing the network organization of automotive firms through a complexity lens, we contend that organizational environments can be described as places operating between order and chaos (Cilliers 1998; Urry 2003). We showed how positive feedback can result in system disturbances. Through the responses of local health and safety representatives, this paper elucidated some of the negative implications that the networked automotive productions system has for local plant environments, specifically in the area of health and safety. In addition, in the case of joint health and safety committees, we revealed the cybernetic character of this negative feedback mechanism and how this information transfer facilitates reactions to health and safety issues and ultimately, acts as an ordering mechanism in local plant environments. The networked character of this system reveals the increase in knowledge transfer resulting from this morphology and the effects of internal disturbances in one phase space for other nodes in the system. In explicating the effects of these systems on local phase spaces, we contribute to the current literature on complexity theory which previously has not been empirically grounded in the lived experiences of people effected by complex systems. In considering the role of negative feedback loops, this paper engaged in a form of "ontological politics" (Law and Urry 2004), by suggesting the potential of these mechanisms to soften the effects of this system on workers in plant environments. Suggesting mechanisms for change to systems takes the position that we are not enamored by systems, but move to enact more beneficial realities for those that bear the effects of complex systems that are in disequilibrium.

\section{REFERENCES}

Aidt, Toke and Zafiris Tzannatos. 2002. Unions and Collective Bargaining. Washington: World Bank.

Braverman, Harry. 1974. Labour and Monopoly Capital. New York: Monthly Review Press.

Barney, Darin. 2004. The Network Society. Cambridge: Polity.

Beck, Ulrich. 2000. The Brave New World of Work. Cambridge: Polity Press.

Bennett, David. 2002. Health and safety management systems: Liability or asset? Journal of Public Health Policy 23(2):153-171. 
Borgatti, Stephen P. and Pacey Foster. 2003. The network paradigm in organization research: A review and typology. Journal of Management 29 (6):991-1013.

Byrne, David. 1998. Complexity Theory and the Social Sciences: An Introduction. London: Routledge.

2005. Complexity, configurations and cases. Theory, Culture \& Society 2 (5):95-111.

Campolieti, Michele and John N. Lavis. 2000. The silent payer speaks: Workers' compensation boards and Canadian physicians. Canadian Medical Association Journal 162(8):1152-1153.

Capra, Fritjof. 1997. The Web of Life: A New Synthesis of Mind and Matter. London: Flamingo Books.

Carlan, Niki, Alan Hall, Ellen McEachen, and Dale Spencer. 2007. Knowledge creation and diffusion in the Ontario auto parts sector. Paper presented at the Work, Employment and Society Conference, Aberdeen, Scotland.

Casper, Steven and Bob Hancke. 1999. Production regimes: ISO 9000 standards in the French and German car industries. Organization Studies 20(6):962-985.

Castells, Manuel. 1996. The Rise of the Network Society. Oxford: Blackwell. 2000. Materials for the exploratory theory of the network society. British Journal of Sociology 51(1):5-24. 2001. The Internet Galaxy: Reflections on the Internet, Business and Society. Oxford: Oxford University Press.

Cilliers, Paul. 1998. Complexity and Postmodernism. London: Routledge.

Clegg, Stewart, Martin Kornberger, and Carl Rhodes. 2005. Learning/becoming/ organizing. Organization 12(2):147-167.

Clement, Wallace and John Myles. 1994. Relations of Ruling, Class and Gender in Postindustrial Societies. Montreal and Kingston: McGill-Queen's University Press.

Clott, Christopher B. 2004. Perspectives on global outsourcing and the changing nature of work. Business and Society Review 109(2):153-170.

Cutcher-Gershenfeld, Joel, Thomas Kochan, and John Wells. 1998. How do labour and management view collective bargaining? Monthly Labour Review 121:23-32.

Deyo, Frederick C. 1996. Introduction: Social reconstruction of the world automobile industry. Pp. 1-20 in Frederick C. Deyo, ed., Social Reconstructions of the World Automobile Industry: Competition, Power and Industrial Flexibility. New York: St. Martin's Press.

Du Gay, Paul. 1994. Colossal immodesties and hopeful monsters: Pluralism and organizational conduct. Organization 1(1):125-48. 2000. In Praise of Bureaucracy. London: Sage. 
Eaton, Adrienne and Thomas Nocerino. 2000. The effectiveness of health and safety committees: Results of a survey of public-sector workplaces. Industrial Relations 39(2):265-290.

Fairris, David and Hironori Tohyama. 2002. Productive efficiency and the lean production system in Japan and the United States. Economic and Industrial Democracy 23(4):529-554.

Gatrell, Anthony C. 2004. Complexity theory and geographies of health: A critical assessment. Social Sciences and Medicine 60:2661-2671.

Gereffi, Gary. 1994. The organization of global buyer-driven commodity chains: How US retailers shape overseas production networks. Pp. 95-122 in G. Gereffi and M. Korzeniewicz, eds., Commodity Chains and Global Capitalism. Westport, CT: Praeger.

Gladwell, M. 2000. Tipping Points: How Little Things can Make a Big Difference. Boston: Little, Brown and Co.

Graham, Laurie. 1995. On the Line at Subaru-Isuzu: The Japanese Model and the American Worker. Ithaca, NY: ILR Press.

Hall, Alan, Anne Forrest, Alan Sears and Niki Carlan. 2006. Making a difference: Knowledge activism and worker representation in joint OHS committees. Relations Industrielles/Industrial Relations 61(3):408-436.

Harrington, H. James. 1999. ISO 14000 Implementation: Upgrading your EMS Effectively. New York: McGraw-Hill.

Hayles, N. Katherine. 1991. Chaos and Order: Complex Dynamics in Literature and Science. Chicago, IL: University of Chicago Press. 1999. How We Became Posthuman. Chicago: University of Chicago Press.

Holland, John H. 1998. Emergence: From Chaos to Order. Oxford: Oxford University Press.

Humphrey, John. 2003. Globalization and supply chain networks: The auto industry in Brazil and India. Global Networks 3(2):121-141.

Kallinikos, Jannis. 2004. The social foundations of the bureaucratic order. Organization 11(1):13-36.

Kartha, C.P. 2004. A comparison of ISO 9000: 2000 quality systems standards, QS9000, ISO/TS 16949 and Baldridge criteria. The TQM Magazine 16(5):331-340.

Kochan, Thomas and Russell Lansbury. 1997. Conclusions. Pp. 303-323 in T. Kochan and R. Lansbury, eds., After Lean Production. New York: Cornell University Press.

Kramer, Desre and Richard Wells. 2005. Achieving buy-in: Building networks to facilitate knowledge transfer. Science Communication 26(4):428-444. 
Landsbergis, Paul, Janet Cahill, and Peter Schnall. 1999. The impact of lean production and related new systems of work organization on worker health. Journal of Occupational Psychology 4(1):108-130.

Lash, Scott and John Urry. 1994. Economies of Signs and Space. London: Sage.

Law, John. 1994. Organization, narrative, strategy. Pp. 248-68 in J. Hassard and M. Parker, eds., Towards a New Theory of Organizations. London: Routledge.

Law, John and John Urry. 2004. Enacting the social. Economy and Society 33(3):390-410.

Leslie, Deborah and David Butz. 1998. GM suicide: Flexibility, space, and the injured body. Economic Geography 74(4):360-378.

Letiche, Hugo and David Boje. 2001. Phenomenal complexity theory and the politics of organization. Emergence 3(4):5-31.

Lewchuk, Wayne and David Robertson. 1996. Working conditions under lean production: A worker-based benchmarking study. Asia Pacific Business Review 2(4):60-81.

Lewchuk, Wayne, A. Leslie Robb, and Vivian Walters. 1996. The effectiveness of Bill 70 and joint health and safety committees in reducing injuries in the workplace: The case of Ontario. Canadian Public Policy 22(3):225243.

Linge, G.J.R. 1991. Just-in-time: More or less flexible. Economic Geography 67(4):316-32.

Maasen, Sabine and Peter Weingart. 2000. Metaphors and the Dynamics of Knowledge. London: Routledge.

MacEachen, Ellen, Judy Clarke, Renee-Louise Franche, and Renee Irvin. 2006. Systematic review of the qualitative literature on return to work after injury. Scandinavian Journal of Work, Environmental and Health 32(4):257-269.

Mitleton-Kelly, Eve. 2003. Complex Systems and Evolutionary Perspectives of Organisations. London: Elsevier.

Nichols, Theo. 1997. The Sociology of Industrial Industry. London: Mansell.

Occupational Disease Panel. 1997. Report to the Workers' Compensation Board on the Health Effects of Occupational Exposure to Fluids Used for Machining and Lubricating Metal in Manufacturing: Cancer of the Rectum. Toronto: Ministry of Labour.

O'Grady, John. 2000. Joint health and safety committees: Finding a balance. Pp. 162-197 in Terrance Sullivan, ed., Injury and the New World of Work. Vancouver: UBC Press.

Parsons, Talcott. 1977. Social Systems and the Evolution of Action Theory. New York: The Free Press. 
Perrow, Charles. 1984. Normal Accidents: Living with High Risk Technologies. New York: Basic Books.

Piore, Michael J. and Charles F. Sabel. 1984. The Second Industrial Divide: Possibilities for Prosperity. New York: Basic Books.

Power, Michael. 1997. The Audit Society: Rituals of Verification. Oxford: Oxford University Press.

Prigogine, Ilya. 1997. The End of Certainty. New York: Free Press.

Rinehart, James, Christopher Huxley, and David Robertson. 1997. Just Another Car Factory? Lean Production and its Discontents. Ithaca: ILR Press.

Rutherford, Tod D. 2000. Re-embedding, Japanese investment and the restructuring buyer-supplier relations in the Canadian automotive components industry during the 1990s. Regional Studies 34(8):739-751.

Sabel, Charles F. 1993. Learning by monitoring. Pp. 137-165 in Neil Smesler and Richard Swedberg, eds., The Handbook of Economic Sociology. Princeton, NJ: Princeton University Press.

Seppala, Pentti and Soili Klemola. 2004. How do employees perceive their organization and job when companies adopt principles of lean production? Human Factors and Ergonomics in Manufacturing 14(2):157-180.

Serres, Michel. 1982. The Parasite. Baltimore, MD: Johns Hopkins University Press.

Shannon, Harry, Lynda Robson, and Joanna Sale. 2001. Creating healthier and safer workplaces: The role of organizational factors and job characteristics. American Journal of Industrial Medicine 40:319-334.

Spencer, Dale. 2007. Governing at-a-distance: Outsourcing, network prudentialism and quality assurance standards. Unpublished manuscript.

Thrift, Nigel. 1999. The place of complexity. Theory, Culture and Society 16(3):31-70.

Urry, John. 2003. Global Complexity. Cambridge: Polity.

2004. Small worlds and the new social physics. Global Networks 4(2):109-130.

2005a. The complexity turn. Theory, Culture and Society 22(5):1-14. 2005b. The complexities of the global. Theory, Culture and Society 22(5):235-254.

Weil, David. 1999. Are mandated health and safety committees substitutes for or supplements to labor unions? Industrial and Labor Relations Review 52(3):339-360.

Womack, James P., Daniel T. Jones, and Daniel Roos. 1990. The Machine That Changed The World. New York: Harper Collins.

Womack, J., and D. Jones. 1996. Lean Thinking: Banish Waste and Create Wealth in your Corporation. New York: Simon \& Schuster. 
Yates, Charlotte, Wayne Lewchuk, and Paul Stewart. 2001. Empowerment as a trojan horse: New systems of work organization in the North American automotive industry. Economic and Industrial Democracy 22:517-541.

Young, S. Mark. 1992. A framework for successful adoption and performance of Japanese manufacturing practices in the United States. Academy of Management Review 17(4):677-700.

Zullo, Roland. 2004. In-sourcing as a strategy for reclaiming union work. Labour Studies Journal 29(1):91-108.

Dale Spencer is a $\mathrm{PhD}$ candidate in sociology at Carleton University. He has a co-authored piece in Criminology and Criminal Justice. Research interests include sociology of organizations, sociology of emotions, critical criminology, sociology of sport and masculinities.

Niki Carlan is a Ph.D. candidate at the University of Windsor. Her areas of interest include the creation, transfer, and dissemination of knowledge; occupational health and work organization; participatory action research; and transdisciplinary methodologies. She has an article in Industrial Relations and has published on women's health issues. 